\title{
Event duration memory: The effects of delay-interval illumination and instructional cuing
}

\author{
B. KENT PARKER and ROGER L. GLOVER \\ West Virginia University, Morgantown, West Virginia
}

\begin{abstract}
The effect of interference treatments on pigeons' working memory for event duration was investigated, using a successive matching-to-sample procedure. In three experiments, birds were trained to match different keylight durations $(2$ or $6 \mathrm{sec}$ ) to different comparison colors (red or green) following delays of 0 to $12 \mathrm{sec}$. The interfering effect of delay-interval illumination and illumination change was assessed in Experiments 1 and 2. It was found that the absolute levels of houselight illumination influenced delayed matching accuracy. Birds trained with houselight illumination showed larger decrements in matching accuracy with increasing delays than did birds trained with darkened delay intervals. In addition, increases in delay-interval illumination relative to baseline produced greater interference with delayed matching accuracy than did decreases in houselight illumination relative to baseline. In Experiment 3, the effect of interpolated instructional cues to remember or forget was examined. As in other directed forgetting experiments employing conventional modality characteristics as the samples to be remembered, it was found that instructional cues to forget, presented during the delay interval, reduced matching accuracy compared to instructional cues to remember. It was concluded that these findings support models of temporal memory that assume temporal information is coded into categorical information onto some nontime dimension over models that assume temporal information is remembered amodally as specific time durations.
\end{abstract}

A number of recent experiments have employed delayed matching-to-sample (DMTS) procedures to investigate pigeons' short-term memory for time or event duration (Cohen, Calisto, \& Lentz, 1981; Kraemer, Mazmanian, \& Roberts, 1985; Spetch \& Wilkie, 1983; Wasserman, DeLong, \& Larew, 1984). Experimental interest in temporal memory stems in part from the nature of event duration as a stimulus dimension. The discrimination and remembering of temporal attributes differs in several ways from discrimination involving conventional modality characteristics as the stimulus attributes to be remembered. Event duration, unlike color or auditory frequency, cannot be responded to differentially until the shortest duration has terminated. More importantly, duration, like the attributes of location, number, and intensity, is common to all stimuli and must be abstracted from all sensory modalities (see, e.g., Meck \& Church, 1982; DeLong \& Wasserman, 1985). Meck and Church showed that rats abstract both duration and temporal location from modality-specific aspects of a signal; they suggested, as have others (DeLong \& Wasserman, 1985; Gibson, 1969), that animals may have specialized systems for the analysis of amodal information. These unique characteristics suggest that event duration may be processed differ-

Portions of these data were presented at the annual meeting of the Psychonomic Society, Boston, MA, 1985. Reprint requests should be addressed to B. Kent Parker, Department of Psychology, West Virginia University, Morgantown, WV 26506-6040. ently from modality-specific stimulus dimensions. More specifically, there may be dissimilarities between pigeons' working memory for event duration and their memory for more conventional stimuli, to the extent that they are not influenced in the same way by the same experimental variables.

Studies investigating pigeons' memory for the duration of a stimulus have found with both choice (Cohen et al., 1981; Spetch \& Wilkie, 1983) and successive DMTS (Wasserman et al., 1984) that matching accuracy declines as an orderly function of delays between sample durations and the subsequent comparison stimuli, in a manner similar to that found in studies manipulating modality characteristics (e.g., Roberts \& Grant, 1976). However, since little is known about the effects of variables other than delay length, the experiments reported here were undertaken to determine whether event-duration memory reacts to interference treatments in the same way as memory for modal attributes. Accordingly, two variables known to affect the amount of forgetting during the delay interval separating sample from comparison were manipulated: delay-interval illumination (e.g., Cook, 1980; Grant \& Roberts, 1976; Kendrick \& Rilling, 1984) and the presentation during the delay of instructional cues to remember or to forget the sample (e.g., Grant, 1981; Kendrick, Rilling, \& Stonebraker, 1981; Maki \& Hegvik, 1980). Both variables have been shown to substantially reduce delayed matching performance with sample stimuli differing in modal stimulus attributes. 


\section{EXPERIMENT 1}

The purpose of the first experiment was to assess the effects of illumination on pigeons' delayed matching of event duration. A number of studies have found that changes in delay-interval illumination interfere with delayed matching of modality-specific dimensions such as color and line orientation (Cook, 1980; Grant \& Roberts, 1976; Roberts \& Grant, 1978; Tranberg \& Rilling, 1980). Experimental predictions concerning the effect of delay-interval illumination on matching accuracy with event duration must take into account both the temporal information abstracted from the modality-specific aspects of the signal and the memory code laid down by this information (Herman \& Forestell, 1985). If temporal information is remembered as the specific time duration presented (e.g., Spetch \& Wilkie, 1983), there is no reason to expect light manipulation to be effective in disrupting this memory code, since light is not from the same physical continuum as the coded information (see, e.g., Maki, Brokofsky, \& Berg, 1979). This view receives indirect suppport from Wilkie's (1983) finding that memory for the amodal characteristic of spatial location is not disrupted by houselight presentations during the sample, delay, or comparison phases of a DMTS task with pigeons. On the other hand, if durations are coded into categorical information onto some dimension other than time (Church, 1980)-for example, a response instruction to peck visually differentiated comparison keys (Kraemer et al., 1985), or a visual memory trace of stimulus onset (Shimp, 1981)-then illumination should disrupt delayed matching accuracy.

The present experiment used a successive matching procedure in which birds were trained to match two different keylight sample durations to two different comparison colors following delays of from 0 to $12 \mathrm{sec}$. That is, responding to a red comparison stimulus was reinforced only following a short (2-sec) sample duration, and responding to a green comparison stimulus was reinforced only after a long (6-sec) sample duration. Responding to the comparison stimulus was not reinforced during other sample-comparison combinations (short-green or long-red). Ambient illumination (houselight) conditions were manipulated between subjects. Throughout the experiment, the houselight was on for half of the subjects during all trial phases (sample, delay, comparison, and intertrial interval). For the remaining subjects, the houselight was off during all trial phases.

\section{Method}

\section{Subjects}

Six experimentally naive male White Carneaux pigeons, maintained at approximately $80 \%$ of their free-feeding weights and housed individually, served as subjects.

\section{Apparatus}

The experimental chamber was a standard one-key unit, with inside dimensions of $30 \times 30 \times 34 \mathrm{~cm}$. The response key, $2.5 \mathrm{~cm}$ in diameter, was centered on the front wall above a $5 \times 6 \mathrm{~cm}$ maga- zine opening. A multistimulus projector was mounted behind the key so that various colors and line tilts could be presented as stimuli. The chamber was equipped with a ventilation fan and continuous white noise was delivered through a speaker mounted behind the response wall of the chamber. In addition, a feedback relay provided a discrete click for functional responses to the key. General illumination was provided by a $15-\mathrm{W}$ ac houselight centered in the ceiling of the experimental chamber. All experimental dependencies and response measures were arranged and recorded by programming equipment located in an adjoining room.

\section{Procedure}

Preliminary and baseline training. Following magazine training, all subjects were trained to peck a white response key. After reliable keypecking was established, each subject received successive matching with 0 -sec delays until stable performance was achieved. Each session consisted of 120 trials. Trials began with the transillumination of the response key with white light for a short (2-sec) or long (6-sec) duration. Immediately after the termination of the sample stimulus the response key was illuminated with either a red or green light. On matching trials (2-sec/red and 6-sec/green) the first peck to the red or green comparison stimulus after $4.5 \mathrm{sec}$ produced a 3-sec grain reinforcer. On nonmatching trials $(6-\mathrm{sec} / \mathrm{red}$ and $2-\mathrm{sec} /$ green), the keylight terminated automatically after $5 \mathrm{sec}$. On reinforced trials, the intertrial interval (TT) began immediately after the comparison stimulus terminated. In each case, the ITI was $25 \mathrm{sec}$ in duration.

For Birds 1, 2, and 3, the houselight remained illuminated throughout each session (HL-ON). Birds 4, 5, and 6 spent each session in darkness (HL-OFF). These houselight conditions remained in effect for all of Experiment 1. The birds were exposed to these experimental arrangements until all had achieved a stable performance with discrimination ratios above $\mathbf{8 5}$. Discrimination ratios were calculated by dividing the rate of responding to comparison stimuli on matching trials by the rate of responding to comparison stimuli on matching plus nonmatching trials.

Delayed matching-to-sample. Following acquisition at the 0-sec delay, each bird received multiple delays. The procedural details of this phase were identical to those of the acquisition phase, except that delays of $0,2,4,6,9,10$, and $12 \mathrm{sec}$ were interpolated between the offset of the sample stimulus and the onset of the comparison stimulus. In addition, each session consisted of 140 trials with each delay programmed to occur equally often on matching and nonmatching trials. All subjects were exposed to this experimental arrangement until stable performance was achieved. Stability was defined as a deviation of less than .05 from the mean discrimination ratio for each delay interval for 3 consecutive days. Stability was assessed independently for each bird.

\section{Results}

\section{Acquisition}

Figure 1 shows the matching performance of each bird during the 0 -sec delay baseline training. All birds acquired high levels of discrimination accuracy during this phase. The mean discrimination ratio for the 6 birds over the last 5 days of training was .92 . All birds exceeded .85 discrimination ratios in an average of 21 sessions (range 12-39). There were no systematic differences in levels of accuracy or rate of acquisition between HL-ON and HL-OFF subjects.

\section{Delays}

When the variable-delay procedure was first introduced, each bird's performance was near chance at all delay 


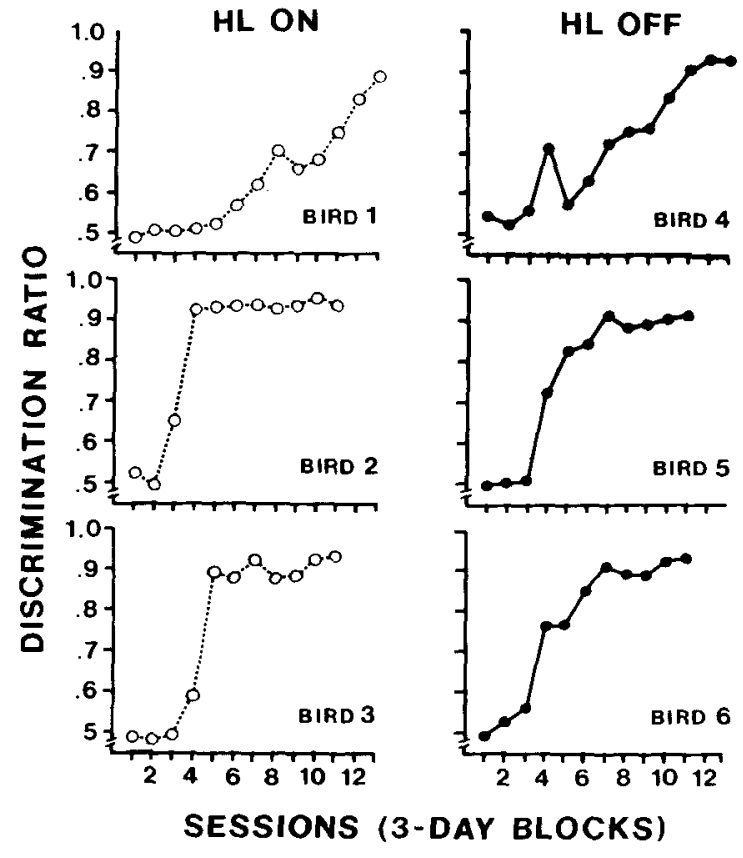

Figure 1. Discrimination ratios for each subject during 0-delay baseline training as a function of 3-day blocks. $\mathrm{HL}=$ houselight.

values. With the exception of Bird 1, discrimination ratios gradually improved throughout the remaining session and reached stability in an average of 50 sessions (range 47-69). Bird 1's performance improved only slightly with extended training in this condition and he was subsequently dropped from further experiments.

Figure 2 shows discrimination ratios for each bird during the last five sessions of the experiment as a function of the delay interval. With the exception of Bird 1, each bird demonstrated excellent (above .80) discrimination accuracy for the 2-sec delay condition, with orderly decreases in accuracy as delays increased. HL-ON subjects (Birds 2 and 3) showed sharper decreases in discrimination accuracy than did HL-OFF subjects (Birds 4, 5, and 6) as delays increased. With 2- and 4-sec delays, HLON subjects were slightly less accurate (.81) than were HL-OFF subjects (.83). However, at the 6-sec delay, HLON subjects (.73) dropped sharply below the mean for the HL-OFF birds (.81). The performance of HL-OFF and HL-ON subjects continued to diverge as delays increased, reaching mean discrimination ratios of .71 and .55 , respectively, at the 12 -sec delay.

These results were confirmed by an ANOVA incorporating delays $(2,4,6,8,10$, and $12 \mathrm{sec})$ and houselight conditions, with Bird 1's data excluded from the analysis. Significant effects were found for delay $[F(5,15)$ $=43.77, p<.001]$, houselight condition $[F(1,3)=$ $11.66, p<.05$ ], and the delay $\times$ houselight interaction $[F(5,15)=4.32, p<.025]$. It was also found that HLOFF subjects required significantly fewer mean sessions to stability criterion (51) than did HL-ON subjects (72) $[F(1,3)=4.32, p<.025]$.

\section{Discussion}

The major finding of Experiment 1 was that matching accuracy varied according to the absolute level of ambient illumination. Moreover, since the houselight condition did not systematically influence the acquisition of 0 -sec matching, the finding, in the variable-delay phase, that birds exposed to the HL-OFF condition reached criterion in fewer sessions and showed better matching accuracy with increasing delays than did subjects in the HL-ON condition argues for the position that the illumination variable produced its effects during the delay interval.

These data are consistent with the findings of several investigations of DMTS performance with monkeys, employing colors and geometric figures as samples (D'Amato \& O'Neill, 1971; Etkin, 1972; Salmon \& D'Amato, 1981 ), and suggest that the absolute level of delay-interval illumination affects pigeons' working memory for the duration of visual events. This finding contrasts with Wilkie's (1983) finding that memory for the amodal characteristic of spatial location of visual stimuli is not affected by visual distractors; it lends support to models of the retention of stimulus duration that assume that pigeons, after being presented with visual-event-duration sample stimuli, code temporal information in terms of sensory-specific (i.e., visual) stimuli (Kraemer et al., 1985; Shimp, 1981), rather than retention models that assume that information is not coded into another dimension but is remembered as the specific time durations presented (Spetch \& Wilkie, 1983). That is, the finding that interpolated light lowers matching performance suggests that visual information is maintained in the memory

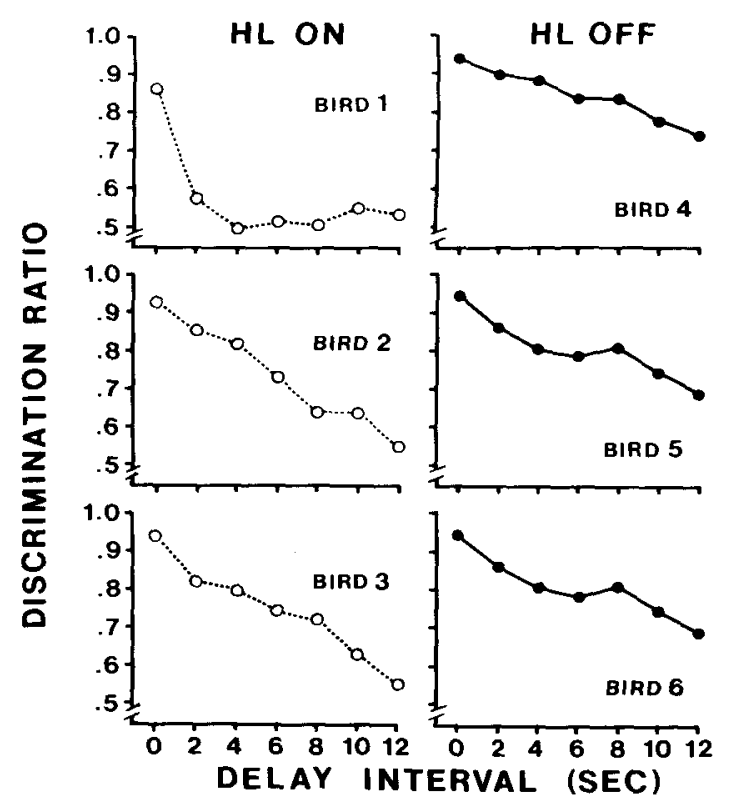

Figure 2. Discrimination ratios for HL-ON and HI-OFF subjects during the last 5 days of Experiment 2 as a function of delay interval. $\mathbf{H L}=$ houselight. 
code, either solely or in conjunction with amodal information.

\section{EXPERIMENT 2}

The finding from Experiment 1 that houselight illumination during the delay interval reduced matching accuracy, relative to a dark delay interval, is inconsistent with the findings of two recent investigations (Cook, 1980; Tranberg \& Rilling, 1980). These studies suggested that the absolute level of illumination is not a factor in pigeons' DMTS performance with colors and line patterns as stimuli. They demonstrated that a change in illumination, relative to the baseline, produced decreases in matching accuracy. Therefore, Experiment 2 was designed to assess the effect of changes in delay-interval illumination on event-duration memory.

\section{Method}

\section{Subjects and Apparatus}

The subjects (Birds 2, 3, 5, and 6) and apparatus were the same as those used in Experiment 1.

\section{Procedure}

Baseline. After completing Experiment 1, the 4 subjects in this experiment were trained under baseline conditions in which delays of 0,4 , and $8 \mathrm{sec}$ were programmed to occur in a pseudorandom fashion during the 120 trials of each session. There were 40 trials per session at each delay, of which 20 were matching trials and 20 were nonmatching trials. In all other procedural details, this experiment was identical to Experiment 1. As in Experiment 1, Birds 2 and 3 spent the entire baseline period with the houselight illuminated (HL-ON), and Birds 5 and 6 spent the baseline period in darkness (HL-OFF). Each subject continued in this baseline condition until it achieved stable performance at each delay.

Testing. After achieving stable performance, each subject was exposed to five test sessions on consecutive days. Each session consisted of 120 trials, 40 at each delay. The independent variable was a change in delay-interval illumination relative to illumination during baseline sessions. Accordingly, illumination levels were changed on 50\% of the trials per session at the 4- and 8-sec delays for each subject. That is, each bird received 20 trials with delay-interval darkness and 20 trials with houselight illumination at the 4- and 8-sec delays. Houselight conditions during the 0 -sec delay trials remained identical to baseline conditions.

For HL-ON subjects (Birds 2 and 3), darkness during the delay interval represented a change from baseline, whereas delay intervals with the houselight illuminated represented a change in conditions for HL-OFF subjects (Birds 5 and 6). Houselight conditions during the sample, comparison, and ITI phases of a trial remained as they had been during baseline sessions. Following the test sessions, the original baseline conditions were reinstated.

\section{Results}

Figure 3 shows discrimination ratios for the last three baseline sessions, the five test sessions, and the 3-day baseline-recovery sessions for each subject at 0-, 4-, and 8-sec delays. As the figure shows, changes in delayinterval illumination relative to baseline conditions disrupted delayed matching performance in each bird tested. With the 4-sec delay, the mean discrimination ratio for no-change trials was .79 , compared to a mean of .59 for
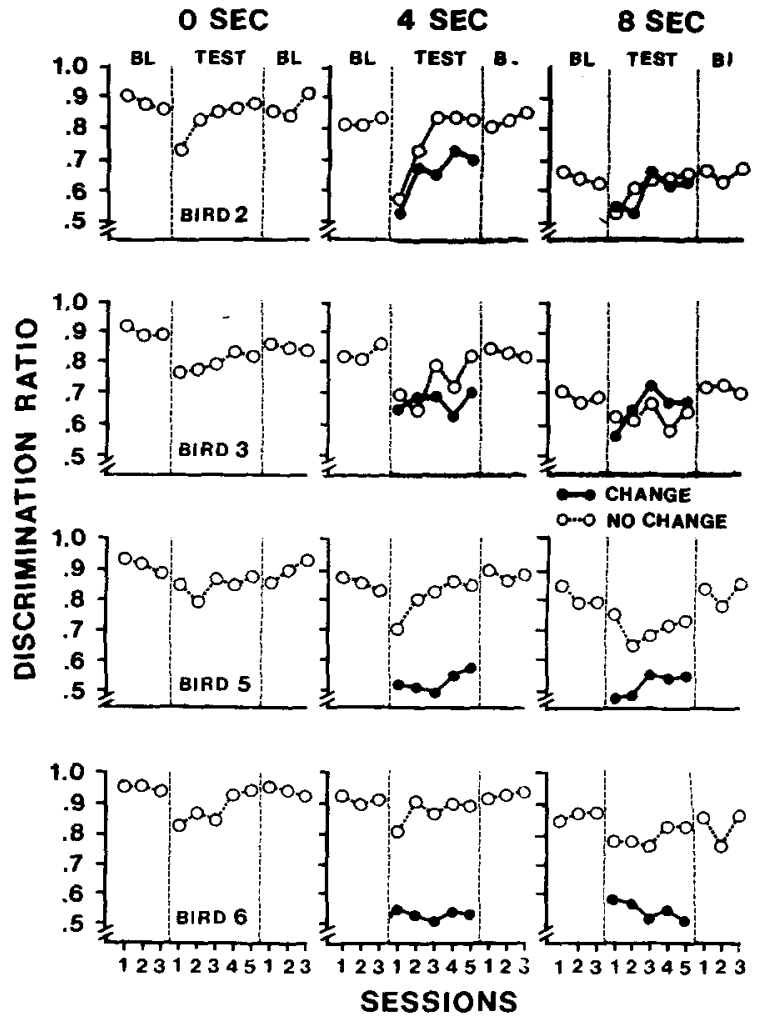

Figure 3. Discrimination ratios for the last three baseline sessions, five test sessions, and three baseline recovery sessions for each subject at 0-, 4-, and 8-sec delays. For houselight-on subjects (Birds 2 and 3 ), the change during the test sessions was a decrease in delayinterval illumination. For houselight-off subjects (Birds 5 and 6), the change was an increase in illumination. $\mathrm{BL}=$ baseline.

change trials. With the 8-sec delay, these means were .70 and .58, respectively. Moreover, HL-OFF subjects (Birds 5 and 6) showed more dramatic decreases in matching accuracy when the houselight was illuminated during the delays than did HL-ON subjects (Birds 2 and 3) when the delay interval was dark. At the 4-sec delay, the mean decrease in discrimination ratios for HL-OFF subjects under illumination conditions was .31; for HL-ON subjects under darkened delay-interval conditions, the mean decrease was .09. At the 8-sec delay, the mean decrease for HL-OFF subjects was .21, whereas the average matching performance of HL-ON subjects was unaffected by change in delay-interval illumination.

These results were confirmed by separate ANOVAs on discrimination ratios at 4- and 8-sec delays. The factors were houselight condition during baseline (HL-ON vs. HL-OFF) and change in delay-interval illumination (change vs. no change) $[F(1,2)=320, p<.001]$; the interaction of change with the baseline illumination condition was also significant $[F(1,2)=96.8, p<.01]$. Similar results were found at the 8-sec delay. Both change $[F(1,2)=35.39, p<.05]$ and the baseline illumination $x$ change interaction $[F(1,2)=34.89, p<.05]$ were significant. These significant interactions statistically con- 
firm the observation that increases in delay-interval illumination produced greater decreases in matching accuracy than did decreases in delay-interval illumination.

\section{Discussion}

Some of the results of the present experiment are consistent with earlier published findings on pigeons' DMTS performance under illumination-change conditions with visual modality characteristics as the sample stimuli. First, when the change in the delay interval was an increase in ambient illumination, the decreases in matching performance were immediate and substantial (Kraemer \& Roberts, 1984; Thompson, Van Hemel, Winston, \& Pappas, 1983; Wilkie, Summers, \& Spetch, 1981). Specifically, accuracy dropped to near-chance levels in the first test session and remained at substantially lowered levels throughout the five test sessions at both 4- and 8sec delays. Moreover, the effects of the change in illumination did not generalize to no-change trials. Second, when the change in illumination was a decrease, relative to baseline, matching accuracy declined at the 4-sec delay (Cook, 1980; Tranberg \& Rilling, 1980); however, the interference effect of the change to delay-interval darkness was not large at the 4-sec delay and failed to materialize at the 8-sec delay.

Other results of Experiment 2 are unique and suggest that increases in delay-interval illumination (relative to baseline) produce greater deficits in pigeon's eventduration memory than do reductions in illumination. Although this finding is not incompatible with models of pigeons' working memory that emphasize the coding of sensory-specific visual information, it runs contrary to the results of Tranberg and Rilling (1980), who used red and green lights as sample stimuli. They reported that illumination increases and decreases during the delay interval resulted in approximately equal deficits in matching accuracy. It is not immediately apparent why illumination increases should be more disruptive than decreases with event-duration stimuli; however, this finding is consistent with the results of Experiment 1 in showing that the absolute level of delay-interval illumination affects pigeons' event-duration memory.

\section{EXPERIMENT 3}

Using key colors as discriminative stimuli, several recent studies of DMTS and delayed successive matchingto-sample have demonstrated that instructional cues presented during the delay interval can influence matching accuracy (Grant, 1981, 1984; Kendrick et al., 1981; Maki \& Hegvik, 1980; Santi \& Savich, 1985). In these directed-forgetting experiments, the acquisition of delayed matching is followed by the presentation of remember and forget cues (orthogonal to sample and comparison stimuli) during the delay interval. On remember-cued trials, the trial terminates with the usual comparison phase; on forget-cued trials, the comparison phase is omitted. Af- ter extensive training with this postsample cuing procedure, the pigeons' memory for the sample following forget cues is tested with occasional probe trials. The typical finding is that matching accuracy is substantially reduced on forget-cued trials, relative to remember-cued trials.

The theoretical interpretation of this finding with the greatest degree of support is the rehearsal hypothesis. This hypothesis proposes that pigeons actively process or rehearse in working memory information derived from the sample during the delay interval. The purpose of Experiment 3 was to extend previous findings by exploring whether pigeons are capable of selectively maintaining temporal information derived from a visual signal.

\section{Method}

\section{Subjects and Apparatus}

Birds 2, 3, 4, and 6 were used in this experiment. Birds 2, 3, and 6 had previously served in Experiments 1 and 2. Bird 4 had participated only in Experiment 1. The apparatus used in Experiments 1 and 2 was again employed.

\section{Procedure}

Baseline. The 4 subjects in this experiment first received baseline training with $0-, 4-$, and 8 -sec delays. They received 120 trials per session, with 40 trials at each delay. All other procedural details during baseline were identical to those of Experiment 1. Birds 2 and 3 were trained with the houselight on (HL-ON) and Birds 4 and 6 were trained with the houselight off (HL-OFF).

Comparison-omission. After each subject had reached stability in the baseline condition, remember $(R)$ and forget $(F)$ cues were presented during the delay interval in each of the 120 trials. The $R$ cue was a white vertical line on a black background and the $F$ cue was a white horizontal line on a black background. Either an $\mathbf{R}$ or an $\mathbf{F}$ cue was presented on the response key during the entire 4- or 8-sec delay interval; each cue was presented on $50 \%$ of the trials at each delay.

Following termination of a delay interval with an $R$ cue, the comparison stimulus was presented; the contingencies were identical to those of the baseline phase. Following termination of a delay interval with an F cue, the comparison stimulus was omitted and the ITI was initiated. This phase was in effect until stable performance (less than .05 change in discrimination ratios on $R$-cued trials for 3 consecutive days) was reached at the 4-sec delay.

Test sessions. After stable performance was achieved in the comparison-omission phase, five probe-test sessions were conducted on consecutive days. Probe-test sessions were identical to sessions in the comparison-omission phase, with the exception that eight $F$ cued trials per session at the 4-sec delay were followed by the presentation of the comparison stimulus. These probe trials were arranged so that four trials were matching trials and four were nonmatching trials.
Results

\section{Comparison-Omission}
During the first 5 days of training, all subjects showed sharp decreases in discrimination ratios as a result of the introduction of delay-interval cues. However, as a con- sequence of extended training (34-37 sessions), ratios returned to near-baseline levels. During the last 3 days of the comparison-omission phase, all subjects' ratios were above .80 at the $4-\sec$ delay. 


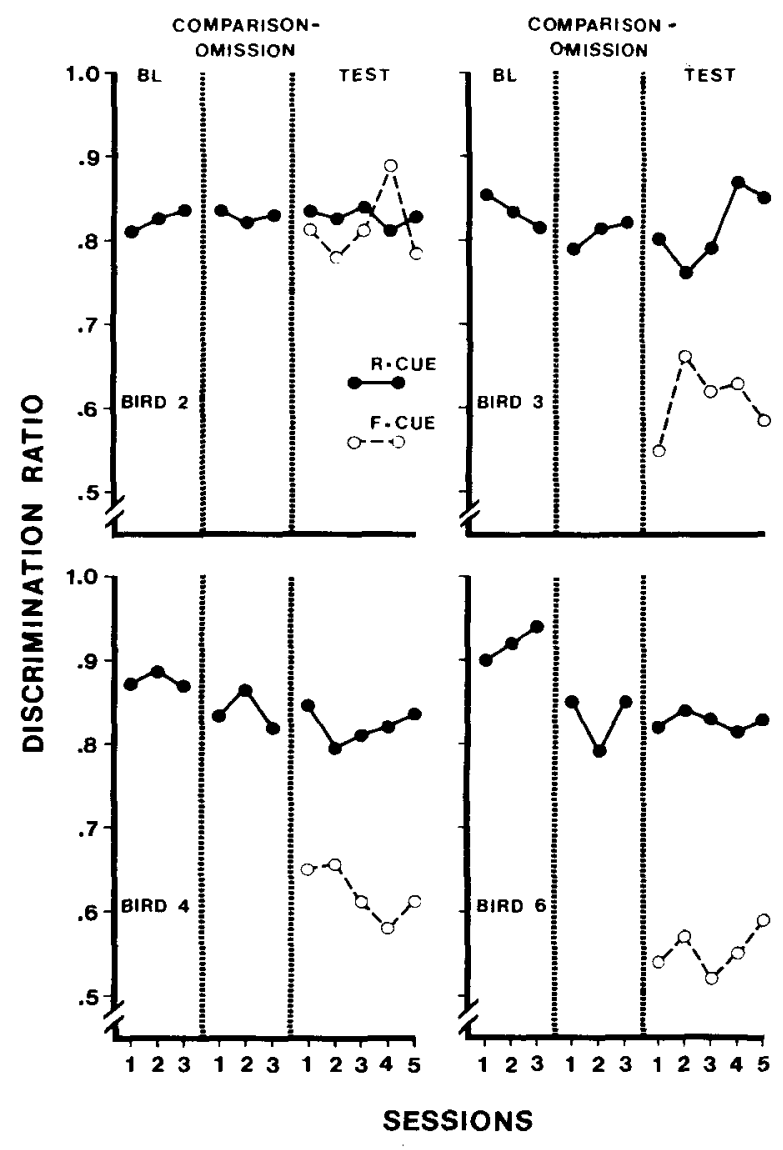

Figure 4. Discrimination ratios for each subject during the last three baseline sessions, the last three comparison-omission sessions, and the five test sessions. For test sessions, the solid line represents remember(R)-cued trials and the dashed line forget(F)-cued trials.

\section{Test Sessions}

Discrimination ratios for each subject during baseline, the last 3 days of comparison-omission training, and the five test sessions are shown in Figure 4. In the test sessions, discrimination ratios for F-cued probe trials were substantially lower than those for R-cued probe trials for 3 of the 4 subjects. For the five test sessions, the mean discrimination ratio was .83 on R-cued probe trials and .66 on F-cued probe trials. An ANOVA incorporating cue condition (R-cued vs. F-cued probe trials) and houselight condition (HL-ON vs. HL-OFF) confirmed this result. A significant effect was found for cue conditions $[F(1,2)$ $=13.08, p<.05]$, indicating that the $F$ cue effectively reduced control by the sample durations. No significant effects were found for houselight $[F(1,2)=1.04$, $p<.05]$ or the interaction of cue and houselight $[F(1,2)$ $=1.8, p<.05]$.

\section{Discussion}

The results of Experiment 3 clearly demonstrate that event-duration matching accuracy, like matching accuracy with conventional modality characteristics, is strongly in- fluenced by the presentation of instructional cues. In 3 of the 4 subjects tested, $F$ cues presented during the delay interval effectively eliminated control, as shown by the reduction of matching accuracy to near-chance levels. Thus, presentation of F cues selectively reduces pigeons' working memory for temporal information. This finding closely parallels the findings of studies demonstrating instructional control with modal stimulus attributes as the to-be-remembered stimuli (Grant, 1981, 1984; Kendrick et al., 1981; Maki \& Hegvik, 1980; Maki, Olson, \& Rego, 1981; Santi \& Savich, 1985) and adds to the generality of directed forgetting in pigeons.

\section{GENERAL DISCUSSION}

The general purpose of these experiments was to examine whether memory for event duration parallels memory for modality attributes in terms of susceptibility to interference treatments. At issue is whether temporal attributes of events are processed in basically the same way as are other attributes (see, e.g., Michon, 1972), or are processed differently because of the unique properties of duration as a stimulus dimension (DeLong \& Wasserman, 1985; Meck \& Church, 1982).

Experiments 1 and 2 examined the extent to which delay-interval illumination disrupts memory for event duration, as it does for modality-specific attributes. The major findings were as follows. First, the absolute level of delay-interval illumination influenced delayed matching accuracy in pigeons. Birds exposed to houselight illumination during baseline showed greater decreases in matching accuracy with increasing delays than did birds exposed to dark delay intervals during baseline. This finding is in agreement with those of Salmon and D'Amato (1981), who examined monkeys' DMTS performance with modal stimuli; but it appears to contrast sharply with the findings of two recent studies (Cook, 1980; Tranberg \& Rilling, 1980) in which the absolute level of illumination did not affect pigeons' delayed matching accuracy with modal stimulus characteristics as the sample stimuli. However, since both of the latter studies were designed to assess the effects of changes in houselight illumination, their experimental designs were inadequate to evaluate the effects of absolute delay-interval illumination during baseline. In Cook's (1980) study, all of the birds received baseline training in the houselight-on condition. In Tranberg and Rilling's (1980) experiments, birds received baseline training in both houselight-on and houselight-off conditions; however, as Salmon and D'Amato (1981) argued, it is difficult to assess the role of the absolute level of illumination from Tranberg and Rilling's data because houselight illumination was manipulated both between and within subjects, and ITI illumination levels were also manipulated.

Second, both increases and decreases in delay-interval illumination interfered with delayed matching accuracy in Experiment 2. This finding resembles those of Cook (1980), Tranberg and Rilling (1980), and several others 
(Grant \& Roberts, 1978; Kendrick \& Rilling, 1984; Roberts \& Grant, 1978; Thompson et al., 1983; Wilkie et al., 1981), and suggests that memory for event durations and memory for modal characteristics are qualitatively similar, at least in that both are affected by changes in ambient illumination. This contrasts with Wilkie's (1983) finding that pigeons' memory for the amodal characteristics of spatial location is not affected by changes in general illumination. Thus, changes in illumination appear to affect the remembering of colors, forms, and durations, but not key location.

Third, increases in delay-interval illumination relative to baseline produced greater interference with delayed matching accuracy than did decreases in illumination levels relative to baseline. This finding appears to conflict with Tranberg and Rilling's (1980) finding, with colors as sample stimuli, of approximately equal memorial deficits with increases and decreases in illumination; however, as Salmon and D'Amato (1981) concluded, the experimental design employed by Tranberg and Rilling did not permit evaluation of the relative magnitude of interference effects resulting from the direction of change in delay-interval illumination. At any rate, it seems clear from the present data (Experiment 2) that event-duration memory was disrupted more by illumination increases than by decreases, and this strongly indicates that illumination per se has powerful effects on pigeons' working memory, independently of the effects of change in illumination.

The findings of Experiments 1 and 2 are inconsistent with models of temporal memory that assume that temporal information is not coded in another dimension (Spetch \& Wilkie, 1983), but is remembered amodally as specific time durations. As argued earlier, the difficulty with this conception is that there is no reason to expect either absolute delay-interval illumination or change in delay-interval illumination to disrupt memory for specific time durations, since delay-interval light stimuli are not from the same stimulus dimension as the coded temporal attributes. On the other hand, models that assume that temporal information is coded into categorical information onto some nontime dimension (Church, 1980) can accommodate the findings of Experiments 1 and 2 by assuming that the pigeons' memory for event duration was coded on the same dimension as the interfering light stimuli. For example, if temporal stimuli were coded prospectively in terms of a response instruction to peck different key colors during the test phase (e.g., Kraemer et al., 1985), then it would be expected that the houselight manipulation would retrospectively interfere with the visually coded response instruction. Similarly, if temporal stimuli were coded retrospectively in terms of the onset of the stimulus cuing the event duration (Shimp, 1981), and if features or attributes of the visually presented stimulus onset progressively decayed, then the houselight manipulation should interfere with the size of the remaining visual memory trace during the test phase. Moreover, it is important to note that, if temporal stimuli were remembered as specific durations of keylight, that is, if sensory-specific visual information were coded in con- junction with abstract temporal attributes (e.g, Meck \& Church, 1982), then delay-interval light would be expected to interfere.

Experiment 3 examined whether pigeons selectively maintain temporal information derived from a visual signal in a directed-forgetting paradigm. It was found that instructional cues to forget the sample, presented during the delay interval, interfered with matching accuracy on probe trials more than did instructional cues to remember. This finding closely resembles those of other directedforgetting experiments, and suggests that event-duration memory, like memory for modal stimulus attributes, involves a process in which memory for the sample is actively processed or rehearsed (Grant, 1981, 1984; Maki, 1981 ), or in which the probability of retrieving the sample memory is reduced by the change in context resulting from $F$ cue presentations (Kendrick et al., 1981; Stonebraker \& Rilling, 1981; Stonebraker, Rilling, \& Kendrick, 1981).

\section{REFERENCES}

Сhurch, R. M. (1980). Short-term memory for time intervals. Learning \& Motivation, 11, 208-219.

Cohen, S. L., Calisto, G., \& Lentz, B. E. (1981). Comparisons of sample stimuli in delayed symbolic matching-to-sample: Some results and implications. The Psychological Record, 31, 77-93.

CooK, R. G. (1980). Retroactive interference in pigeon short-term memory by a reduction in ambient illumination. Joumal of Experimental Psychology: Animal Behavior Processes, 6, 326-338.

D'AмAтo, M. R., \& O'Neill, W. (1971). Effect of delay-interval illuminaton on matching behavior in the capuchin monkey. Journal of the Experimental Analysis of Behavior, 15, 327-333.

DeLong, R. E. \& Wasserman, E. A. (1985). Stimulus selection with duration as a relevant cue. Learning \& Motivation, 16, 259-287.

ETKIN, M. W. (1972). Light produced interference in a delayed matching task with capuchin monkeys. Learning \& Motivation, 3, 313-324.

GiBson, E. J. (1969). Principles of perceptual learning and development. New York: Appleton-Century-Crofts

GRANT, D. S. (1981). Stimulus control of information processing pigeon short-term memory. Learning \& Motivation, 12, 19-39.

GraNT, D. S. (1984). Directed forgetting and intratrial interferences in pigeon delayed matching. Canadian Journal of Psychology, 38, 166-177.

GRANT, D. S., \& RoBERTs, W. A. (1976). Sources of retroactive inhibition in pigeon short-term memory. Journal of Experimental Psychology: Animal Behavior Processes, 2, 1-16.

Herman, L. M., \& Forestell, P. H. (1985). Short-term memory in pigeons: Modality-specific or code-specific effects? Animal Learning \& Behavior, 13, 463-465.

Kendrick, D. F., \& RiLung, M. (1984). The role of interpolated stimuli in the retroactive interference of pigeon short-term memory. Animal Learning \& Behavior, 12, 391-401.

Kendrick, D. F., Riluing, M., \& Stonebraker, R. B. (1981). Stimulus control of delayed matching in pigeons: Directed forgetting. Journal of the Experimental Analysis of Behavior, 36, 241-251.

Kraemer, P. J., Mazmanian, D. S., Roberts, W. A. (1985). The choose-short effect in pigeon memory for stimulus duration: Subjective shortening versus coding models. Animal Learning \& Behavior, 13, 349-354.

Kraemer, P. J., \& Roberts, W. A. (1984). Short-term memory for visual and auditory stimuli in pigeons. Animal Learning \& Behavior, 12, 275-284.

MAKI, W. S. (1981). Directed forgetting in animals. In N. E. Spear \& R. R. Miller (Eds.), Information processing in animals: Memory mechanisms (pp. 199-225). Hillsdale, NJ: Erlbaum.

MAKI, W. S., BROKOFSKY, S., \& BERG, B. (1979). Spatial memory in 
rats: Resistance to retroactive interference. Animal Learning \& Behavior, 7, 25-30.

MAKI, W. S., \& HEGVIK, D. K. (1980). Directed forgetting in pigeons Animal Learning \& Behavior, 8, 567-574.

MAKI, W. S., OLSON, D., \& REgo, S. (1981). Directed forgetting in pigeons: Analysis of cue functions. Animal Learning \& Behavior, 9 , 189-195.

MeCK, W. H., \& ChURCh, R. M. (1982). Abstraction of temporal attributes. Journal of Experimental Psychology: Animal Behavior Processes, 8, 226-243.

Michon, J. A. (1972). Processing of temporal information and the cognitive theory of time experience. In J. T. Fraser, F. C. Haber, \& G. H. Miller (Eds.), The study of time (pp. 242-258). Heidelberg: SpringerVerlag.

RoBerTs, W. A., \& Grant, D. S. (1976). Studies of short-term memory in the pigeon using a delayed matching to sample procedure. In D. L. Medin, W. A. Roberts, \& R. T. Davis (Eds.), Processes of animal memory. Hillsdale, NJ: Erlbaum.

RoBerTs, W. A., \& GrANT, D. S. (1978). An analysis of light-induced retroactive inhibition in pigeon short-term memory. Journal of $E x-$ perimental Psychology: Animal Behavior Processes, 4, 219-236.

Salmon, D. P., \& D'Amato, M. R. (1981). Note on delay-interval illumination effects on retention in monkeys (Cebus apella). Journal of the Experimental Analysis of Behavior, 36, 381-385.

SANTI, A., \& SA VICH, J. (1985). Directed forgetting in pigeons: Remember cues initiate rehearsal. Animal Learning \& Behavior, 13, 365-369.

SHIMP, C. P. (1981). Local structure of steady-state operant behavior. In C. M. Bradshaw, E. Szabodi, \& C. F. Lowe (Eds.), Quantification of steady state operant behavior (pp. 189-203). New York: Elsevier/North-Holland Biomedical Press.
SPETCH, M. L., \& Wilkie, D. M. (1983). Subjective shortening: A model of pigeons' memory for event duration. Journal of Experimental Psychology: Animal Behavior Processes, 9, 14-30.

Stonebraker, T. B., \& Rilling, M. (1981). Control of delayed matching-to-sample performance using directed forgetting techniques. Animal Learning \& Behavior, 9, 196-201.

Stonebraker, T. B., Rilling, M., \& Kendrick D. F. (1981). Time dependent effects of double cuing in directed forgetting. Animal Learning \& Behavior, 9, 385-394.

Thompson, R. K., Van Hemel, P. E., Winston, K. M., \& Pappas, N. (1983). Modality-specific interference with overt mediaton by pigeons in a delayed discrimination task. Leaming \& Motivation, 14, 271-303.

Tranberg, D. K., \& Rilling, M. (1980). Delay-interval illumination changes interfere with pigeon short-term memory. Journal of the Experimental Analysis of Behavior, 33, 39-49.

Wasserman, E. A., Delong, R. E., \& Larew, M. B. (1984). Temporal order and duration: Their discrimination and retention by pigeons. Annals of the New York Academy of Sciences, 423, 103-115.

WILKIE, D. M. (1983). Pigeons' spatial memory: III. Effects of distractors on delayed matching of key location. Joumal of the Experimental Analysis of Behavior, 40, 143-151.

Wilkie, D. M., Summers, R. J., \& SPETch, M. L. (1981). Effect of delay-interval stimuli on delayed symbolic matching to sample in the pigeon. Joumal of the Experimental Analysis of Behavior, 35, 153-160.

(Manuscript received July 2, 1986 ; revision accepted for publication January 6, 1987). 